Konrad WEGENER ${ }^{1 *}$, Sascha WEIKERT ${ }^{1}$, Josef MAYR ${ }^{1}$, Markus MAIER ${ }^{1}$, Vahid Ostad ALI AKBARI ${ }^{1}$, Martin POSTEL ${ }^{1}$

\title{
OPERATOR INTEGRATED - CONCEPT FOR MANUFACTURING INTELLIGENCE
}

\begin{abstract}
Increasing autonomy and sustainability are major goals in manufacturing. Main technological trends provide enablers for achieving these goals and need to be implemented and combined in manufacturing machinery in a suitable manner. The paper exposes a vision of modern manufacturing machines, where the complexity of manufacturing processes is handled within the manufacturing machine and a simplistic front end is presented to the operator, which means that major elements of operators' tasks are fulfilled by the intelligence of the machine. Research vectors paving the ground for this concept from different points of view are then discussed. Research is presented on intelligent grinding, intelligent recognition and suppression of chatter, adaptive thermal and motion error compensation exploting also self-learning abilities. It is necessary to point out, that not only intelligent mastering of process and machine becomes more and more important but communications among machine tools enabling process chain overarching intelligent approaches and creating intelligent factories.
\end{abstract}

\section{INTRODUCTION}

Manufacturing processes are complex and complicated. This especially holds true the stricter the requirements in terms of economy, ecology and part quality become. The term "advanced manufacturing" in the correct sense of the wording is not the trial of new and incapable manufacturing technology approaches, but the realization of products with large serial numbers or exit rates, extremely high and constant quality under ecologic and economic pressure, which is mostly done by technologies developed to highest maturity and being mastered to the utmost possible extent. Mastering of manufacturing processes to this extent requires excellent skills of the operators, which are lacking more and more, and the "keep it simple" approach is an absurdity, if the physics of the process is difficult. The slogan must run "keep it suitable", which requires the right means for the tasks to be fulfilled. And it might be interesting to keep manufacturing simple for the operators, but that means that the

\footnotetext{
${ }^{1}$ Institute of Machine Tools and Manufacturing (IWF), ETH Zurich, Switzerland

*E-mail: wegener@iwf.mavt.ethz.ch

https://doi.org/10.36897/jme/144359/
} 
production machine must be capable of coping with the full complexity of the process under each and every arising condition. Fail safe, self monitoring, self healing, health reserves are then the attributes for advanced manufacturing machinery, granting a high degree of autonomy and reducing the influence of the operators in the day to day production to a minimum. The domain of human intelligence and skills is then engineering in the design, construction and layout phase, the design for $\mathrm{X}$ and especially design for reliability, which becomes a more and more prominent task. Flexible, fast and reliable automation technology is an indispensable characteristic for advanced manufacturing technologies.

Mastering manufacturing processes can be measured by OEE, availabilities, scrap rates, process capability indicators, etc. and scatter of results. Tightening the tolerances then requires to reduce the scatter and increase process and machine understanding. Characteristic for manufacturing is that the manufacturing processes are strongly intertwined with the respective machines and cannot be mastered without knowing the behavior of the machines. Model based technologies digital twins or digital images of processes and machines are the immediate entry points for enhanced mastering of processes. These are the enablers to predict and counteract the systematic part of what for convenience and simplicity is normally subsumed as part of the scatter. Process and machine understanding need therefore to take into account the behaviors under all arising internal and external conditions and includes today some aspects of machine intelligence. Enhanced process understanding is also the precondition for fast startup and first part right, which can drastically increase the productivity.

Given these aspects and requirements of manufacturing, the paper first outlines in Chapter 2 a vision to where the large trends in manufacturing might converge in future. Being still a vision, further chapters contain different approaches in this direction, but all of them are still only individual elements pointing in the direction of this vision. They contribute different approaches for enhanced and intelligent mastering of processes, namely grinding in Chapter 3 and milling in Chapter 4. Intelligent machines for enhancing accuracy are presented in Chapter 5 and 6, approaches, which increase quality and autonomy.

\section{ARTIFICIAL OPERATOR}

From the aforementioned argumentation the role distribution between a human operator and the machine control needs to be re-defined. Certain properties of biological systems shall then be realized in the manufacturing system. Bio-inspiration is not a new topic, but nowadays instead of only copying natural structures the inspiration concerns the adoption of functional properties of biological systems, which offer the opportunity to gain a deeper relieve of the operator and thus higher degree of autonomy. After some preliminary work from Ueda [1] and Malshe et al. [2] the biological transformation in manufacturing was launched Byrne et al. [3]. Also, the keynote paper by El Maraghy et al. [4] rolled out a road map for the future development of manufacturing systems. Fig. 1 introduces a vision of a bio-intelligent manufacturing system, which is conceptualized for laser powder bed fusion, but can be adapted to any other manufacturing technology. Especially manufacturing technologies that are largely dependent on operator's experience are useful to consider in this context, such as 
all the additive technologies, but also grinding and other surface technologies, etc. Important properties in which at least some biological systems are superior to technical systems are the following:

1. Intelligence: Advanced biological systems as mammals have implanted rules to allow them reasoning about environmental signals and react in a complex manner. As this is done according to multiple inputs which are as well external and internal, their behaviour is only partly predictable according to externally predefined rules. This means complexity in the original sense as the decision making of a biological system depends on a large number of parameters, which all have some scatter. Also the decision rules are unsharp and scatter prone.

2. Abundance of sensors: To start reasoning, input signals are required and cognitive capability is needed. All biological systems have sensors in abundance (ie. 10 coldness sensors per $\mathrm{cm}^{2}$ as average on the human skin). These sensors together with their evaluation methodology develop an impression or picture of the surrounding environment, which is as complete as necessary for the organism and its relevance is filtered in the brain. The sensors are organized in sensor networks, which are counterchecked with each other to determine plausibility and have the ability to recalibrate themselves. A large number of animals and especially humans have optical sensors as broad band sensors capturing colour, brightness and direction, as well as broad-band acoustic sensors able to capture loudness, frequency and direction.

3. Exchange of information: Humans and a large number of other biological, living systems communicate, gain additional knowledge, and transfer experience. This completely coincides with the intentions of Industry 4.0, the integration of data from different subsystems, which still today is one of the jobs reserved for human intelligence.

4. Health maintenance: A biological system is able to self-repair (heal damage and adjust for wear) to a certain extent. Biological systems regrow wear layers in joints and skins and thus continually degrade until end of life. They also can abandon functionality and utilize redundancy to counterweight the loss to a certain extent.

5. Functional integration: convincing property of biological structures is not only how well it is adapted to the loads, but how well different functions are integrated within load carrying structures.

The first three properties are the capabilities expected from the machine operator and need to be mapped onto the technical system. Important aspect of the bio-inspired functionality is the degree of integration of the different properties, unprecedented in technology. This includes the already described sensor fusion and mutual plausibility checking, it is part of the health reserve, to relocate functionality at least partially and it is visible in the inclusion of information from outside instead of making own experience.

Core of the concept in Fig. 1 therefore is an expert system, which needs to be connected to all the information providing subsystems, the sensors for environmental influences, for the machine status and the process behavior, the information channels to the outside world by internet with other machines in other application fields and naturally the operator. Though expert systems have been developed in the last two decades of the $20^{\text {th }}$ century as a predefined repository of data, mainly parameters suitable for carrying out manufacturing processes, the term "expert system" is utilized here for a more advanced vault of knowledge, being 
capable to adapt to new situations, to learn and to generate and provide new knowledge out of what has been stored so far.

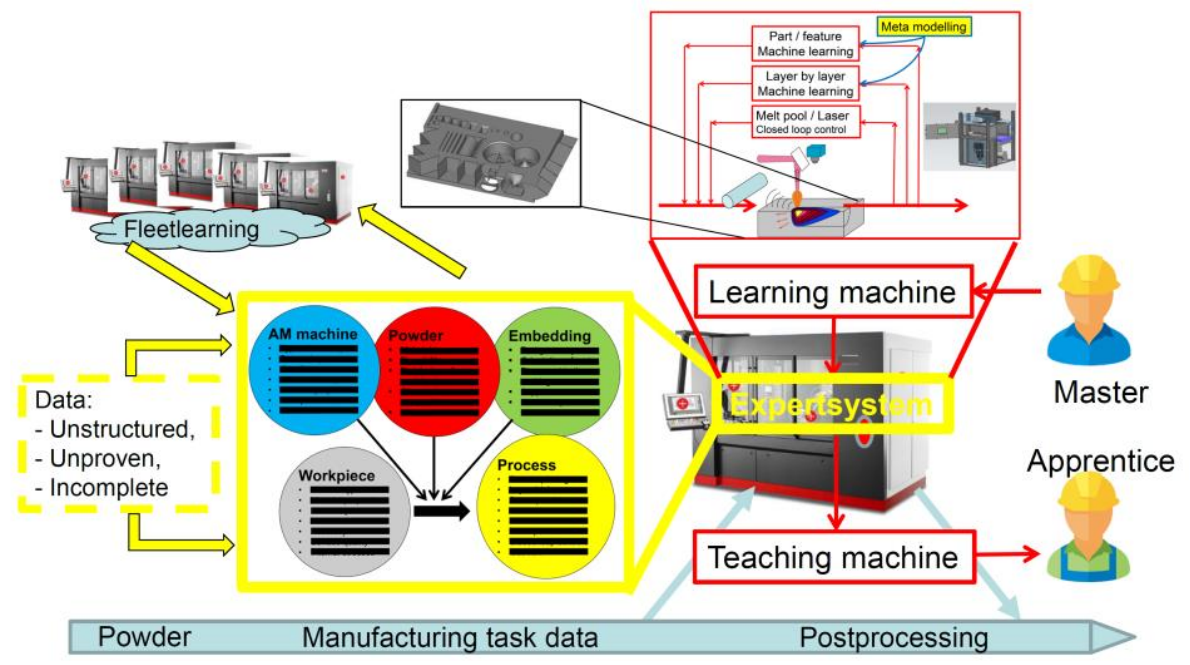

Fig. 1. Concept of an intelligent LPBF-machine (SLM) integrating operator's capabilities for increased autonomy

The old expert systems have been developed under the scope of technologies so far available, and it seems suitable to transfer it to modern approaches. Highest priority has the communication with the operator. Companies are relying on a wealth of implicit knowledge of their employees, which can only be safeguarded with the help of an expert system that is able to learn from the inputs, setup of processes from experienced operators. As setup of the process the manufacturing strategy and the individual process parameters are understood. The whole required information with the individual case must be handed over into the machine to make the process run. Missing is that the machine resp. the expert system must generate autonomously an understanding to apply the available knowledge to similar cases. This is the task of the "learning machine". On the other hand the machine needs to be able to use the acquired knowledge to propose setups for new manufacturing tasks for an unskilled user. A crucial point is to distinguish between the inputs of skilled and unskilled operators, which needs to be done with plausibility checks out of the acquired process understanding. All experience based human knowledge has a certain degree of uncertainty, which must be mirrored in the expert system. The uncertainty of knowledge must be attributed to each piece of information within the expert system. Next important source of information is the data describing the manufacturing task. This concerns the specification of powder, alloy part geometry, quality requirements and batch composition. Powder specification to the preciseness required for the SLM process and its influence on the part quality is still in debate. Therfore the precision requirements of powder specification and what needs to be entered into the machine is unknown. To avoid exaggerated requests from the machine, the observation of the first generated layers and closing the loop with adaptation strategies can solve the problem, but requires the threefold learning loop specified in Fig. 1 and discussed to more detail in [5]. A collection of technologies for self optimizing machines for the sake of autonomy is presented by Möhring et al. [6]. Fleet- and transfer learning requires besides internet connectivity technologies to transfer results found on one machine to 
the other. This is even on the level of machines of the same type not yet satisfactorily solved. A model based approach for the transfer is foreseen. Some work is done in this respect and presented in [7].

Monitoring of the machine's status is one of the requirements for increased autonomy and predictive maintenance, which today is discussed for all the manufacturing equipment and for the SLM system was exposed in [8] The status of the machine, for instance temperature in the building chamber, degree of contamination of optical systems etc. require strategies to circumvent the effect on the quality of the part, which is the very basic approach to self healing, as to a certain extent the absorption of laser power in the optics for instance can be counteracted by increasing the laser power of the beam source.

Most important is the monitoring of the process zone. It is the key stone for increasing part quality and at the same time the autonomy of the machine. In [9] technologies are reviewed. For the sake of robustness multiple layers defined by their time scale of interaction need to be defined and are used to correct the flaws generated by process steps before. At least three layers as indicated in Fig. 1 are necessary. Closed loop control to keep immediate disturbances out of the process and acting between the sensory and the laser power is the mostly applied technology as for example demonstrated in [10]. Flaws within a layer and origins of faults that develop over several layers shall be detected layer wise and a correction strategy needs to be setup in a rule based manner and by application of machine learning [11]. Image recognition technologies based on pretrained neural networks, which are already available and only need tuned to the faults to be recognized are a promising technology here. Still the rule basis needs to be generated but needs to be setup on the detectability of the different flaws. A wealth of monitoring technologies has been developed as collected in [8] and [9]. But for none of them a thorough analysis on the fault detection capabilities has been achieved. Correction strategies and monitoring technologies need to be developed integrated with each other. The outer control loop specifies the learning ability and storage of gained knowledge out of the process monitoring within a vault of technologies, a geometry or part related data base. A human feedback, an automatic feedbak from a subsequential quality assurance step is required to stamp the data as approved. As LPBF is a technology for small serial numbers down to one, learning a strategy for making just this part is not of great usefulness. Therefore a feature separation and feature parametrization respecting critical geometries in LPBF and described in [8] combined with automatic feature recognition is necessary for the setup of a new process. The outer learning cycle then has the task to teach in processing strategies and process parameters to be reused in other part geometries.

The collection of input channels and expected results from the expert system specifies its structure and functionality. The structure is specified in the headlines of the colorful bubbles in Fig. 1. Essential and structuring aspect is the requirement that the different influences need to be computed separately and superposed to other influences. A simple data base as well as neural networks as the first choice of artificial intelligence will not work alone. Requirement is the development of new knowledge out of what has been experienced and is stored in the data vault. The new type of expert systems can be based on ontologies. It needs different intelligence tools. It contains learning tools adapted to the individual tasks. The great potential of artificial neural networks has been pointed out by Barschdorff and Monostori [12], Monostori et al. [13] and Pham and Pham [14]. Artificial neural networks necessarily 
are part of the integrated intelligent machine, but also the rule sets for different tasks, physical models to predict process windows from similar but different situations, may that be similar alloying composition, different particle shapes, different laser beam properties and for the optimization of part orientation and part position within the working space, which both define the build job. Even for the decision whether to start the build job or to wait for better opportunities to better fill the building chamber, tools like partial observable Markov decision processes are available and applicable.

The description concerns a manufacturing process with still scarcely available generalized process planning tools. But it shows stringently that the technology planning needs to be part of the intelligence of the machine, and either the CAM tool has a bidirectional interface to the machine tool be fed and exploited by it, or the CAM tool is tailored directly to the machine. The future belongs to fully integrated intelligent manufacturing systems, which are termed throughout this paper and in accordance to Byrne et al. [15] "biointelligent systems". Fully integrating different information channels, sensors and actuators with AI tools, knowledge base (experience) and reasoning capabilities are required to achieve similar properties like highly developed biological (living) systems and exploit their benefits. Being still a vision in its full elaboration already realized achievements in the direction of this goal and their already visible benefits for manufacturing are rolled out in the remainder of the paper.

\section{GRINDING INTELLIGENCE}

Grinding is a process difficult to control, requiring the selection of various parameters such as cutting speed, feed rate and dressing parameters. Typically, the objective of the parameter selection is to achieve a cost-efficient grinding process and produce parts which fulfil quality requirements without damaging the machine or components. Today process parameters are mainly selected by human operators, using a combination of trial and error and experience. Rowe et al. [16] and Sakakura and [17] introduced already artificial neural networks for the selection of grinding process parameters to master the difficulties to control the process. This chapter shows deficiencies of conventional expert systems together with their amelioration by adding self-learning and self-optimization components.

An approach to automate the selection of process parameters is the use of expert systems, as illustrated in Fig. 2. The main idea of expert systems is to provide knowledge from domain experts to all operators. Therefore, knowledge of domain experts is transferred to a knowledge base by a knowledge engineer. An inference engine utilizes the stored knowledge and provides recommendations to operators through a user interface. Sometimes the recommendation is enhanced by an explanation module to provide reasons for the recommendation. The individual expert systems may differ in the structure of the knowledge representation. Commonly used representations are rule-based systems, such as used in [18] for the optimization of centerless grinding, or case-based systems in combination with adaptive control as proposed in [19]. Expert systems of the elder type have a static knowledge base and lack the learning possibility. 
Figure 3 shows a comparison between the performance of 75 human operators and a grinding expert system, where the performance is evaluated based on the operation time and the degree of feature fulfilment. It can be seen that the operator results vary greatly, clearly showing the improvement potential of today's approach. The task to be solved in Fig. 3 is described as to make 3 cylinders of different diameters within the prescribed tolerance and the required surface quality amounting to 6 properties to be fulfilled.

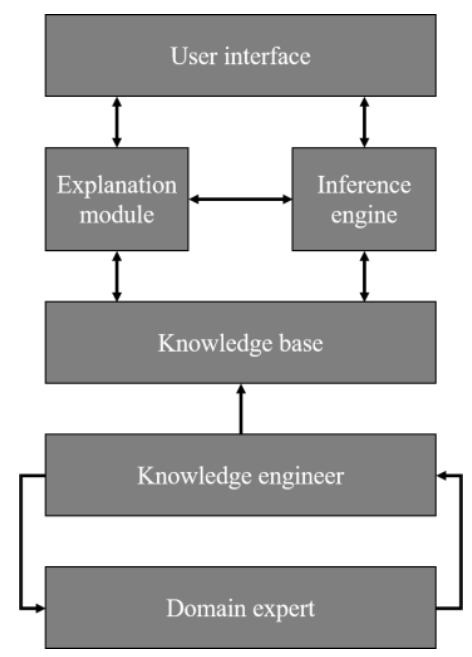

Fig. 2. Structure of a former expert system adapted from [20] and [21] without self-learning ability

The curve of used manufacturing times is per person divided in 6 equidistant segments and becomes green in the first $\mathrm{n}$ segments if $\mathrm{n}$ features fulfilled the requirements. The expert system is able to outperform many human operators, but some operators still show a better performance than the expert system. This result is expected because the expert system by design cannot outperform the knowledge engineer and the domain expert designing the expert system. Therefore, expert systems so far existing typically miss a possibility to autonomously acquire new knowledge and improve over time and heavily depend on the initial knowledge provided by domain experts. Hence, a big challenge for expert systems is the selection of process parameters for new workpieces, machine and / or tool combinations because less precise knowledge is available for such cases.

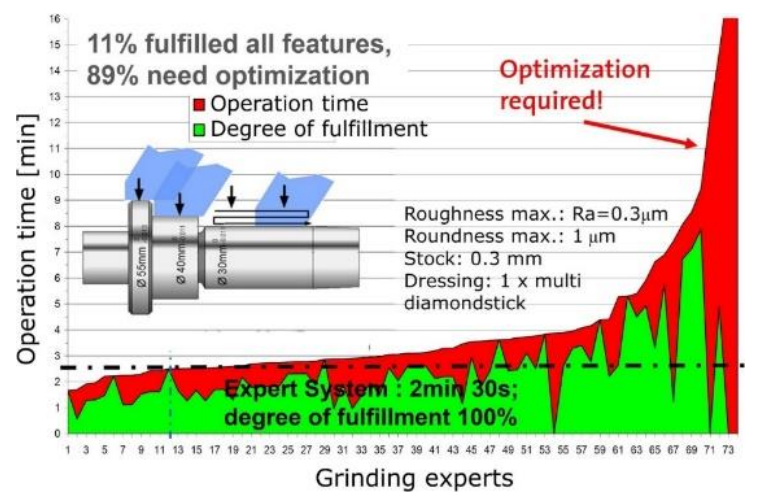

Fig. 3. Operator time and degree of fulfilment for industrial expert systems and human experts according to [22]. 6 properties are required to fulfil. The green part represents the fulfilled requirements. The expert system fulfilled all requirements, but some human grinders were even faster and equally successful 
Table 1. Methods for grinding process optimization from literature

\begin{tabular}{|c|c|c|c|c|}
\hline Source & $\begin{array}{l}\text { Method for } \\
\text { selection of } \\
\text { experiments }\end{array}$ & $\begin{array}{l}\text { Modelling } \\
\text { techniques for } \\
\text { grinding process }\end{array}$ & $\begin{array}{l}\text { Method to determine } \\
\text { optimal parameters }\end{array}$ & Objective \& Constraints on output \\
\hline [23] & $\begin{array}{l}\text { Taguchi } \\
\text { method } \\
\text { (orthogonal } \\
\text { array) }\end{array}$ & $\begin{array}{l}\text { Parametric } \\
\text { regression of } \\
\text { empirical models }\end{array}$ & Genetic algorithm & $\begin{array}{l}\text { Multi-objective optimization of surface } \\
\text { roughness, grinding time, and } \\
\text { production costs constrained to } \\
\text { workpiece removal parameters and } \\
\text { wheel wear parameters }\end{array}$ \\
\hline [24] & $\begin{array}{l}\text { Taguchi } \\
\text { method } \\
\text { (orthogonal } \\
\text { array) }\end{array}$ & $\begin{array}{l}\text { Second order } \\
\text { polynomial fit } \\
\text { (response surface } \\
\text { methodology) }\end{array}$ & $\begin{array}{l}\text { 1) Taguchi (signal to } \\
\text { noise ratio) } \\
\text { 2) Graphically }\end{array}$ & $\begin{array}{l}\text { 1) Minimize geometric error } \\
\text { 2) Minimize geometrical error with } \\
\text { surface roughness and material } \\
\text { removal constraint }\end{array}$ \\
\hline$[25]$ & $\begin{array}{l}\text { Full factorial } \\
\text { design }\end{array}$ & Neural networks & $\begin{array}{l}\text { Combination of } \\
\text { weighting method } \\
\text { (described in [26], } \\
\text { branch and bound } \\
\text { method, and generalized } \\
\text { reduced gradient method }\end{array}$ & $\begin{array}{l}\text { Multi-objective optimization of power, } \\
\text { normal force, surface roughness, and } \\
\text { material removal rate }\end{array}$ \\
\hline [27] & $\begin{array}{l}\text { Fractional } \\
\text { factorial } \\
\text { design }\end{array}$ & Neural networks & $\begin{array}{l}\text { Back propagation } \\
\text { algorithm with } \\
\text { Boltzmann factor }\end{array}$ & $\begin{array}{l}\text { Weighted multi-objective optimization } \\
\text { of material removal rate, surface } \\
\text { roughness, grinding force per width, } \\
\text { and grinding power per width } \\
\text { constrained to a maximum grinding } \\
\text { power per width and a maximum } \\
\text { surface roughness }\end{array}$ \\
\hline $\begin{array}{l}{[28]} \\
{[30]}\end{array}$ & $\begin{array}{l}\text { No } \\
\text { experiments } \\
\text { for } \\
\text { modelling }\end{array}$ & $\begin{array}{l}\text { Empirical models } \\
\text { from literature }\end{array}$ & $\begin{array}{l}\text { [28] } \\
\text { Quadratic programming } \\
\text { [29] } \\
\text { Particle swarm } \\
\text { optimization } \\
\text { [30] } \\
\text { 1) Artificial bee colony } \\
\text { algorithm } \\
\text { 2) Harmony search } \\
\text { algorithm } \\
\text { 3) Simulated annealing } \\
\text { algorithm }\end{array}$ & $\begin{array}{l}\text { 1) Rough grinding: weighted multi- } \\
\text { objective optimization of } \\
\text { production costs and production } \\
\text { rate constrained to thermal damage, } \\
\text { wheel wear, machine tool stiffness, } \\
\text { and surface roughness } \\
\text { 2) Finish grinding: weighted multi- } \\
\text { objective optimization of } \\
\text { production costs and surface finish } \\
\text { constrained to thermal damage, } \\
\text { wheel wear, machine tool stiffness, } \\
\text { and production rate }\end{array}$ \\
\hline [31] & $\begin{array}{l}\text { Taguchi } \\
\text { method } \\
\text { (orthogonal } \\
\text { array) }\end{array}$ & None & Grey relational analysis & $\begin{array}{l}\text { Optimization of material removal rate, } \\
\text { surface roughness, and grinding force }\end{array}$ \\
\hline [32] & $\begin{array}{l}\text { Taguchi } \\
\text { method } \\
\text { (orthogonal } \\
\text { array) }\end{array}$ & None & $\begin{array}{l}\text { Principal component } \\
\text { analysis combined with } \\
\text { grey relational analysis }\end{array}$ & $\begin{array}{l}\text { Optimization of surface roughness, out } \\
\text { of cylindricity, and diametral tolerance }\end{array}$ \\
\hline [33] & $\begin{array}{l}\text { Box- } \\
\text { Behnken } \\
\text { design }\end{array}$ & $\begin{array}{l}\text { Second-order } \\
\text { polynomial fit } \\
\text { (response surface } \\
\text { methodology) }\end{array}$ & $\begin{array}{l}\text { Multi-objective genetic } \\
\text { algorithm }\end{array}$ & $\begin{array}{l}\text { Optimization of vibration and surface } \\
\text { roughness }\end{array}$ \\
\hline [34] & $\begin{array}{l}\text { Central } \\
\text { composite } \\
\text { design }\end{array}$ & $\begin{array}{l}\text { Second-order } \\
\text { polynomial fit } \\
\text { (response surface } \\
\text { methodology) }\end{array}$ & $\begin{array}{l}\text { 1) Non-linear } \\
\text { programming } \\
\text { 2) Genetic algorithm }\end{array}$ & Minimization of surface roughness \\
\hline
\end{tabular}


Another approach to autonomously select process parameters is optimization. The example outlined here presents a tool to transfer the task of selecting process parameters from the operator to the machine. Often, the optimization objective is to minimize production costs while simultaneously fulfilling quality constraints of the final part such as a maximal surface roughness. In general, the optimization procedure consists of methods for experiment selection, process modelling, and methods to determine optimal parameters, as listed in Table 1. Typically, the experiments are selected first using a classical design of experiments (DoE) such as the Taguchi method. Modelling is often achieved by empirical models, polynomial fits and neural networks. After a model of the process is established, the optimal parameters can be determined by optimising the model. Often meta-heuristics such as genetic algorithms or particle swarm methods are used to determine optimal parameters. A key issue with this approach is that simple models such as empirical models and second order polynomial fits typically only show good performance for specific tasks but not for general applications. Flexible models such as neural networks can be applied to very general tasks but require many costly experiments.

To improve the current optimization approaches, [35] demonstrated self-optimization of a grinding process by using adaptive sampling combined with Gaussian process models. Gaussian process models are flexible and provide an uncertainty estimation of the prediction, which is not provided by neural networks. Therefore, flexible Gaussian process models can be combined with only a few data points. In contrast to classical DoE, adaptive sampling uses the model prediction to select experiments, which are informative about the optimum. An acquisition function provides the position of the next experiment as a trade off between the optimality of parameters and lack of knowledge within the parameter space. A typical optimization procedure is shown in Fig. 4. It can be seen that many points are sampled close to the optimum $\left(10^{\text {th }}\right.$ experiment $)$ while areas far away are only sampled sparsely. In this way, optimal parameters are determined with a few experiments.
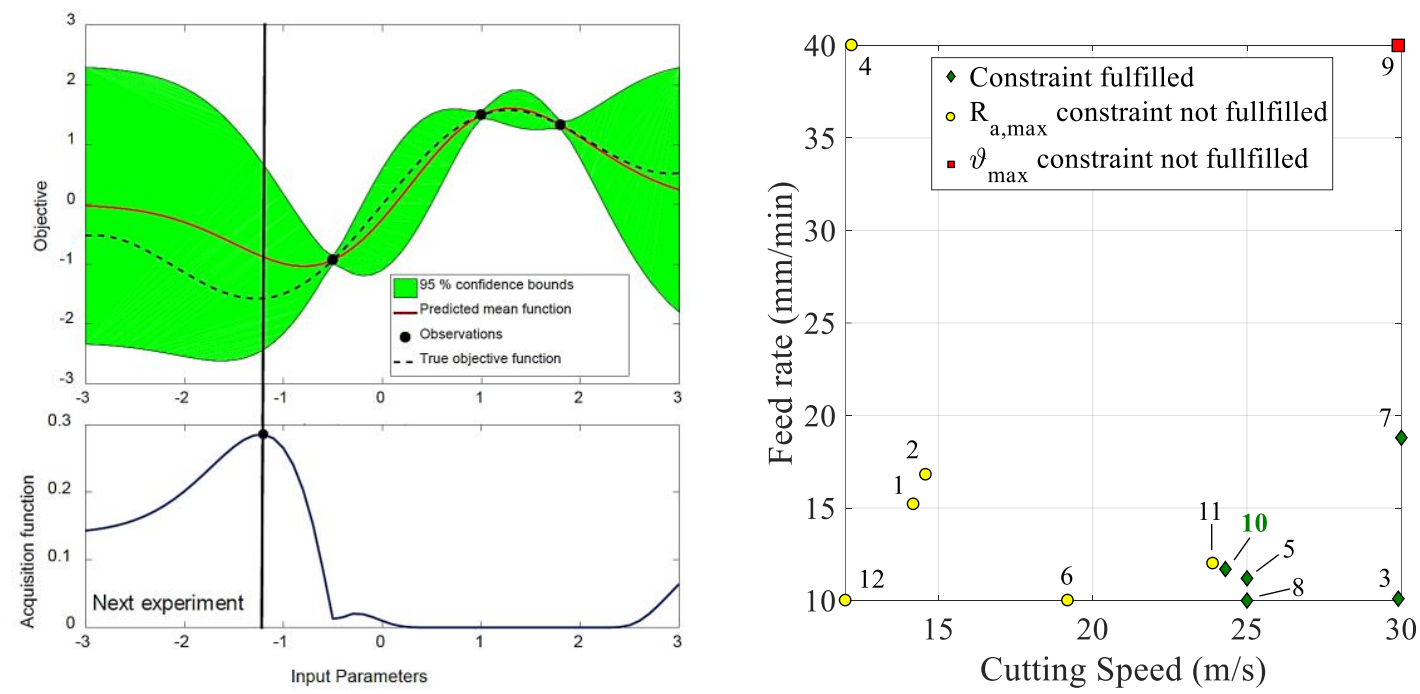

Fig. 4. Gaussian process models combined with adaptive sampling from [35]. Left side presents in green the 95\% confidence interval and the acquisition function, the maximum of which gives the new parameters for the next experiment. Right side shows the parameter space and the parameter points for the subsequent choice of experiments 
In conclusion, expert systems still today are often based on knowledge alone and do not adequately adapt to process responses and changes. Similar issues arise by using simple models for optimization because they have a limited flexibility. By using advanced models it is possible to adapt well to process responses and changes but typically require many costly experiments. An advantage of using adaptive sampling combined with Gaussian process models is that it allows to exploit knowledge gained during the optimization by the acquisition function. To further reduce the number of experiments, including expert knowledge in the optimization is a promising direction for future research.

\section{ADVANCED CHATTER MITIGATION}

Stability lobe diagrams are a well-known method to differentiate stable from unstable cutting conditions and to indicate stability pockets with high productivity in milling [36]. Unstable process conditions lead to self-excited vibrations between the tool and the workpiece, so-called chatter vibrations, which have highly negative consequences such as reduced machine and tool lifetimes and deteriorated workpiece surface qualities. The creation of stability lobe diagrams, however, is typically associated with an extensive measurement effort [37] and the usage of expensive equipment. Besides, model parameters are eventually associated with uncertainties [38] and vary in different machine and process configurations [39]. Consequently, the agreement between predicted and experimentally observed stability limits is not satisfactory and reliable, which prohibits the full exploitation of the stability reserves.

The proposed approaches are steps towards the self-enhancing milling machine in the direction of the vision presented in Chapter 2, which continuously monitors process conditions and stability states of cuts, and which uses this data to yield increasingly precise stability lobe diagrams over time. The approach combines physical modelling and selflearning. Compared to the outcomes of state-of-the-art analytical modelling approaches [40], results show prediction accuracy improvements of more than $40 \%$. Contrasted to state-of-theart algorithms that are solely based on machine learning [41], [42], approximately five times fewer experimental training samples are necessary to reach the same prediction accuracy on a test set.

Three solution examples for this model enhanced machine learning are presented on how neural networks and analytical models for the machine dynamics, the cutting coefficients, and the stability evaluation can be linked to allow for rapid estimation of the shape of the stability lobes. Different from any previously developed approach, any stable or unstable cut recorded during arbitrary cutting operation can be included in the optimizations, and dedicated experiments become obsolete. With the acquisition of more data, the precision of the stability predictions increases over time. These points make the developed approaches valuable tools for an application in a real production environment.

\subsection{NEURAL-NETWORK SUPPORTED INVERSE PARAMETER IDENTIFICATION}

In the first approach [43] with the framework shown in Fig. 5, neural networks are implemented upstream of the stability solution to identify unknown relationships between 
easily measurable and unknown, hard-to-measure parameters. The networks are trained with a genetic algorithm using a cost function that compares model stability predictions with the experimental stability states of the training samples.

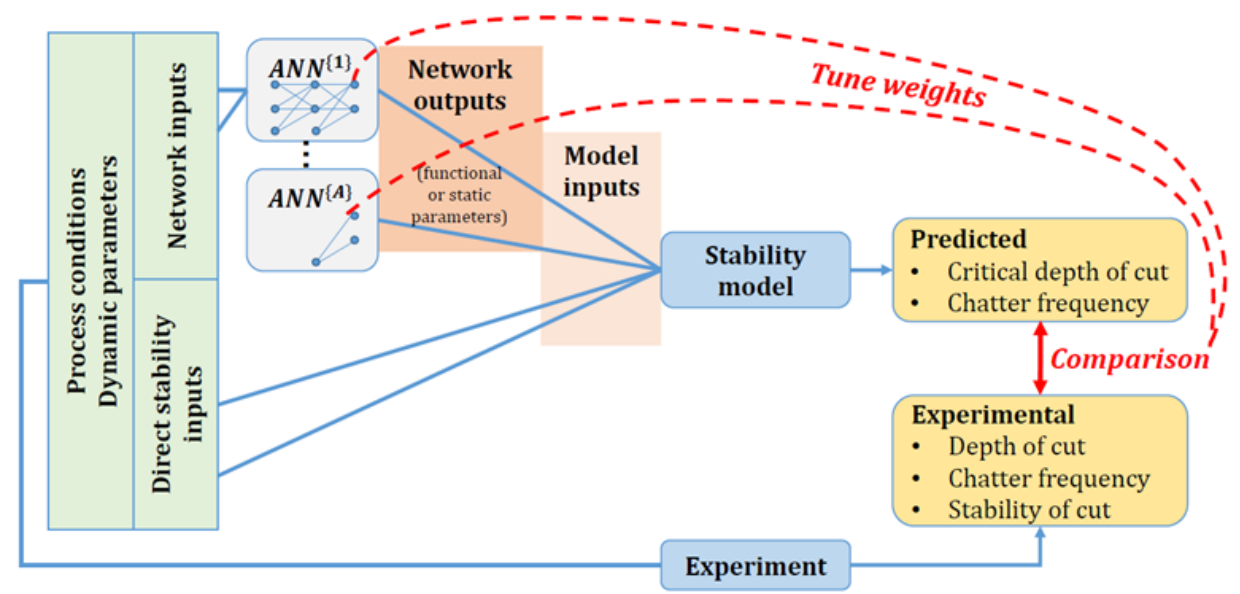

Fig. 5. Framework for neural network supported parameter identification and stability predictions [43]

\subsection{ENHANCED MODULARIZED MODELS OF MILLING MACHINES THROUGH MACHINE LEARNING}

The second approach [44] extends this idea by including a modularized model of the machine structure and of the cutting coefficients, which allows transferring the gained knowledge to new cases with different machine and process configurations. The realized modularization scheme (Fig. 6) is the result of a trade-off between an accurate representation of the behaviour of the single components and a reasonable characterization detail.

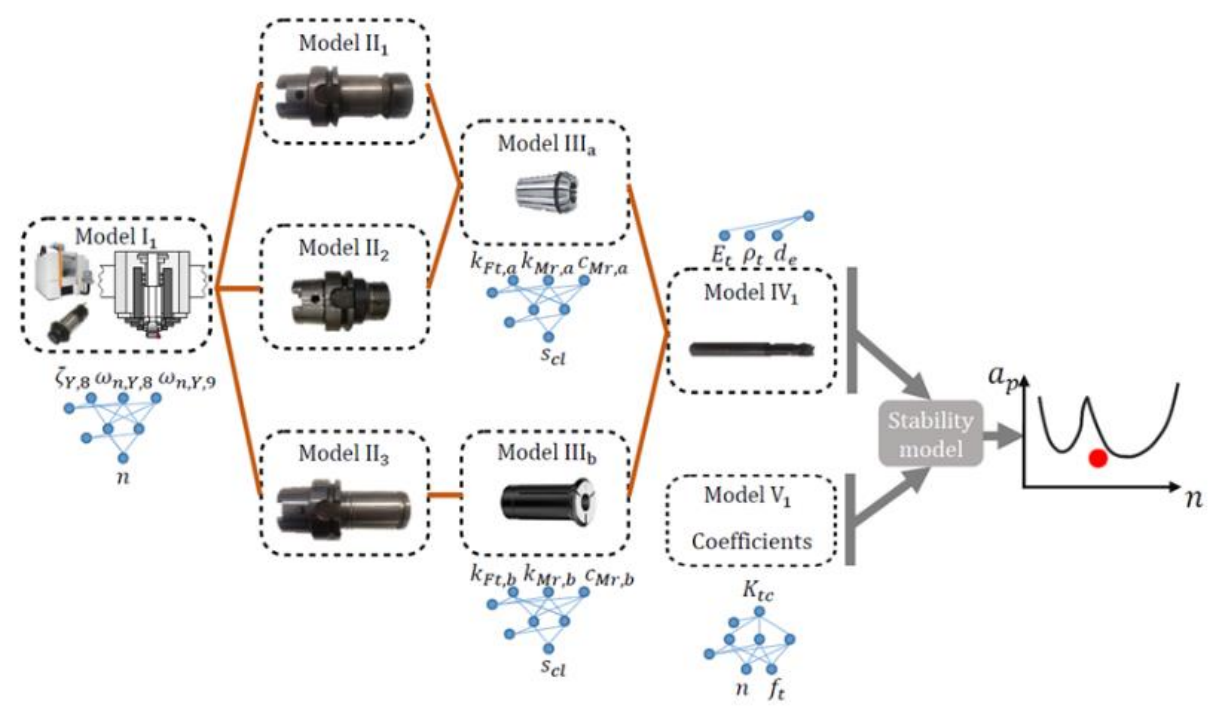

Fig. 6. Schematic representation of an exemplary realization of the proposed model improvement framework [44].

The individual components are represented with physical models and parameters that are self-learned by the machine from every cut executed on the machine 
In the optimization process, the algorithm can correct the assumptions on the model behavior of the components. By introducing a penalty for cases where the algorithm deviates strongly from the expected model parameters, physically reasonable solutions are favoured and the physical interpretability of the results is enabled. Furthermore, the introduction of a sensitivity analysis step helps selecting only the most relevant optimization parameters, and, hence, reduces the computation time significantly.

\subsection{ENSEMBLE DEEP TRANSFER LEARNING}

In the third example, a new hybrid approach for the refinement of stability limits in milling operations is presented [45]. While Deep Neural Networks (DNN) have been used in previous approaches for chatter prediction in milling and turning [42, 46], the methods required a very large amount of data samples for training. Here, a so-called transfer learning approach is used to decrease the number of necessary experimental training samples. It combines knowledge about the general dynamic behavior of spindle-holder-tool assemblies and the resulting shapes of stability lobe diagrams under various cutting conditions with experimental data by employing ensemble transfer learning on deep neural networks. The training is made on numerical results of the model, where an uncertainty about the real values of the model parameters is taken into account. Finally the stability lobe diagrams from different parameter assumptions within a range of expectation are averaged. A detailed overview of this approach is illustrated in Fig. 7 and Fig. 8.

In the first place, simulated stable and unstable points are generated using receptance coupling theory and an analytical stability model. These stability states deviate from the actual, experimentally observed stability states due to the imperfections of the models and uncertainties in the model input parameters. To be able to compensate for these deficiencies, the whole modelling strategy is transferred into a deep neural network by training it with the simulated data. The network is now aware of the general dependencies of the stability boundary on some easily measurable parameters and the concept of stability pockets and takes the uncertainty of model parameters into account.

In the second place, few experimental samples are now used to fine-tune the network and adapt it to the real behavior of the system. The approach hence compensates uncertainties in the modelling stage regarding both uncertain input parameters as well as inaccuracies of the models used. It is further shown that the overall test performance is improved by employing an ensemble learning strategy, where the predictions of multiple networks are combined.

Figure 8 shows the individual predictions for three sample cases mentioned in Table 2 along with the truncated mean of all predictions. It can be seen that, while a significant number of individual predictions diverge strongly from the experimental stability boundary, the truncated mean yields a reasonable estimate of the actual stability boundary.

The presented method avoids any kind of measurement, except for one initial identification of machine tool and spindle dynamics, which could be done at the machine tool manufacturer when the machine leaves the assembly line. This makes it an attractive solution for industrial implementation. 


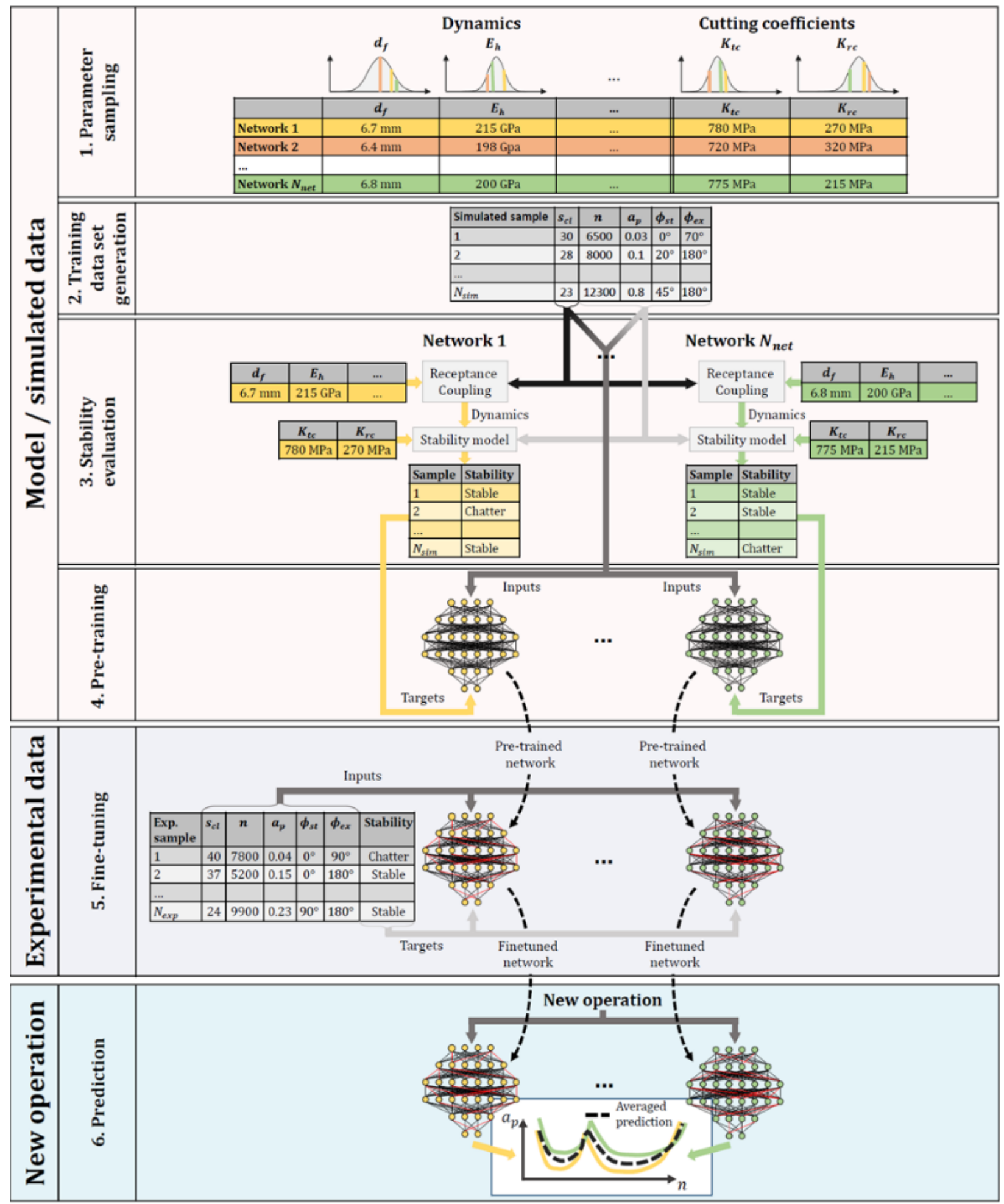

Fig. 7. Ensemble transfer learning strategy with $\mathrm{N}_{\text {net }}$ networks [45]. Step 1: All uncertain parameters are sampled $\mathrm{N}_{\text {net }}$ times from their respective distributions. Step 2: $\mathrm{N}_{\text {sim }}$ samples are generated with random clamping lengths, spindle speeds, and axial and radial engagements. Step 3: Theoretical tooltip dynamics and stability states of the respective samples are evaluated using receptance coupling theory and an analytical stability model. Step 4: The gathered inputs (clamping lengths, spindle speeds, axial and radial engagements) and outputs (stabilities of the simulated cuts) are used for the pre-training of the networks. Step 5: These networks are then fine-tuned using experimental data. Step 6: For a new cutting scenario, the resulting stability predictions of the individual networks are averaged using a truncated 

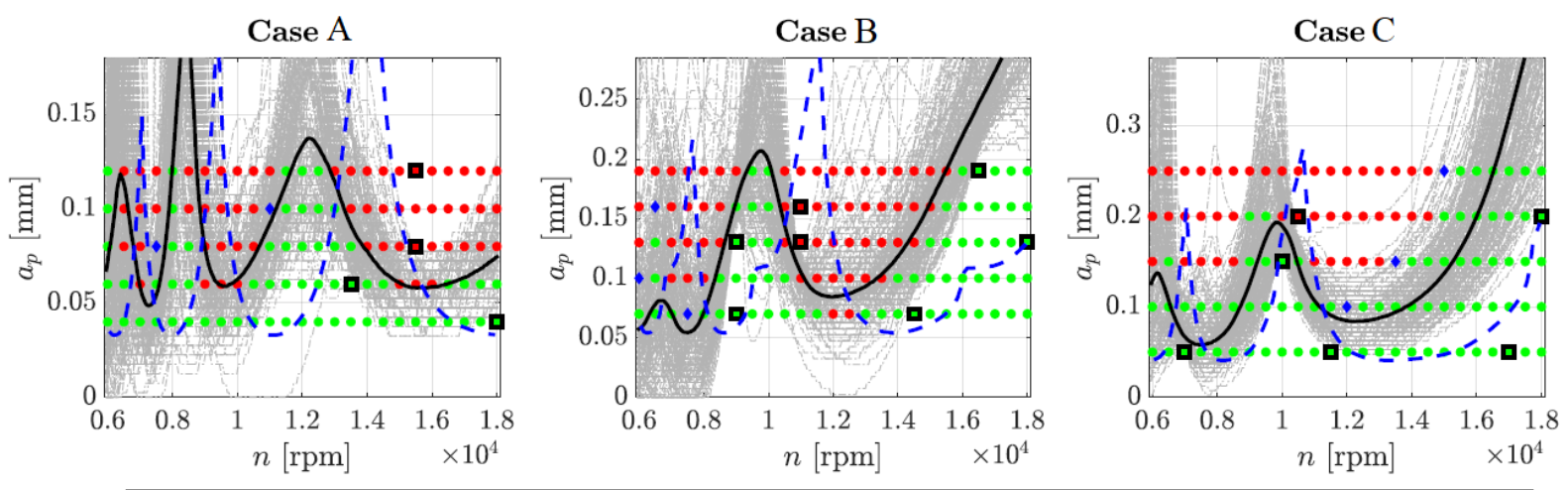

\begin{tabular}{|ll}
\hline - Experiment stable & - Training samples \\
- Experiment marginal & Individual predictions new approach \\
- Experiment chatter & -Ensemble prediction new approach \\
\hline
\end{tabular}

- - Analytical model prediction

Fig. 8. Details on the ensemble prediction in three sample cases: Individual predictions of all 200 networks (grey dashed lines) and resulting ensemble predictions (black continuous lines as averages). Also shown are the predictions of the theoretical model alone (blue dashed lines) [45]

Table 2. Cutting cases and number of cuts (training samples) that were included in the fine-tuning [45]

\begin{tabular}{lrlrrrr}
\hline \multirow{2}{*}{ Case } & Clamping & Milling & \multirow{2}{*}{$\begin{array}{c}\text { Radial } \\
\text { length }\end{array}$} & strategy & immersion & Training samples \\
\hline A & $34.0 \mathrm{~mm}$ & Up & $75 \%$ & 2 & 2 & 4 \\
$\mathrm{~B}$ & $24.8 \mathrm{~mm}$ & Up & $55 \%$ & 5 & 2 & 7 \\
$\mathrm{C}$ & $22.3 \mathrm{~mm}$ & Down & $60 \%$ & 5 & 1 & 6 \\
\hline
\end{tabular}

\section{THERMALLY SELF-EQUILIBRATING MACHINES}

In modern manufacturing of complex workpieces, 5-axis machine tools often face the trade-off between high productivity and high precision. According to Mayr et al. [47] thermal errors have a large impact on the attainable accuracy of machine tools. Either the machines become air-conditioned or the skilled operator is the one that adjusts the machine according to its thermal state. The presented approach is one of the tasks of the intelligent machine, transferring the adjustment tasks from the operator to an intelligent module acting on the machine without operator interference. Model-based compensation strategies are a promising approach to minimize the effect of thermal errors on the overall accuracy of the machine tool. Furthermore, these compensation strategies enable a shift from resource-based design measures towards an intelligence-based procedure to improve the precision of produced workpieces. Especially phenomenological compensation models, as presented for example by Gebhardt et al. [48], Brecher et al. [49] and Mareš et al. [50], are frequently applied to reduce the occurring thermal errors of machine tools. However, databased phenomenological compensation models can result in inaccurate compensation when thermal boundary conditions arise which are absent from the underlying data for the parameter identification. Therefore, Blaser et al. [51] developed the Thermal Adaptive Learning Control (TALC), which combines phenomenological compensation models and automatic on-machine measurements to increase the long-term robustness of phenomeno- 
logical compensation models. Consequently, the TALC enables an automated and rule-based adaption of the model parameters even after the initial model training phase as presented by Mayr et al. [52]. The TALC uses as phenomenological models autoregression with exogenous inputs (ARX).

This allows a precise representation of the dynamic system behavior, compared to the static models which are often used in industry [53]. In comparison to the model parameters, the model inputs of the original TALC are predefined and cannot be adapted during the compensation phase. To further improve the self-learning capability Zimmermann et al. [54] extended the TALC by the adaptive input selection method. The concept of the TALC without and with adaptive input selection is shown in Fig. 9.

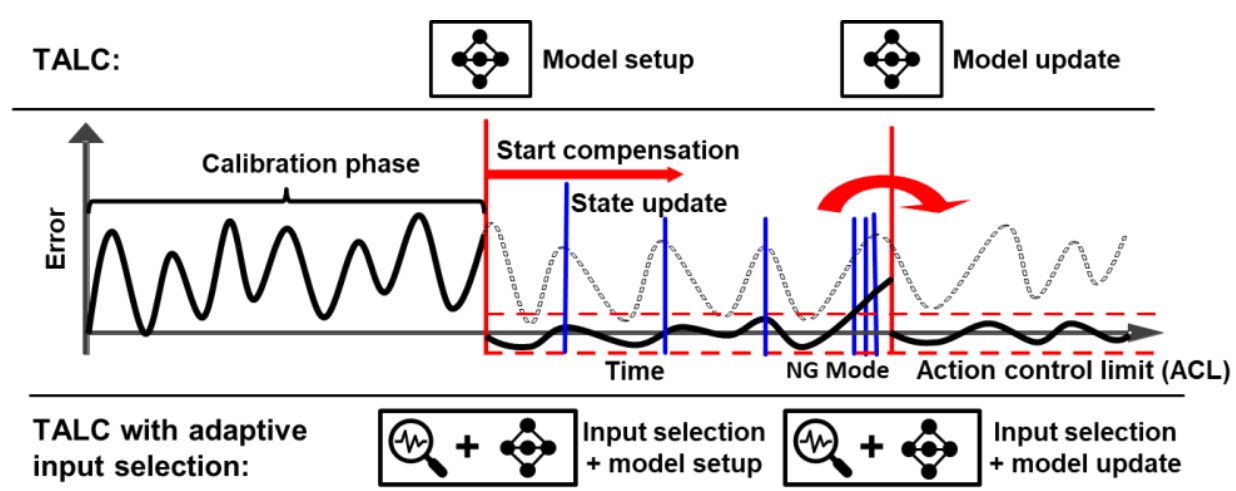

Fig. 9. Concept of the TALC and the adaptive input selection method adapted from [54]. After the training phase of the phenomenological model, where the parameters are identified, the errors become reduced (blackline in comparison to dashed grey line). While temperature sensors provide the input for the phenomenological model, the validation is done by geometrical measurements from time to time (blue vertical lines). If an out-of-tolerance situation (NG mode) is detected, the phenomenological model is updated by more frequent measurements. Adaptive input selection then in addition allows to select the most relevant temperature sensors

The adaptive input selection method enables an automatic and individual selection and reselection of the inputs from all available sensors for the phenomenological compensation model of each considered thermal error. Consequently, the self-learning ability of the model setup and the model updates are significantly increased, and the required operator interaction to setup the TALC is further reduced. Fig. 10 exemplarily illustrates the compensation results for the thermal error Ez0T applying the TALC and the adaptive input selection method to a random speed profile of the $\mathrm{C}$-axis as presented by Zimmermann et al. [54].

Zimmermann et al. [54] also show that the adaptive sensor selection method not only increases the self-learning capabilities but also improves the robustness of phenomenological compensation models even in the case of short model training. The increased robustness of the thermal compensation models due to recalibration of the model inputs is illustrated in Fig. 11. In the case of the static sensor set the model inputs are only selected once after the initial model training. During the compensation phase, only the model parameters are updated. As explained by Zimmermann et al. [54] the exceedances of the action control limit can be reduced from seven to two using the adaptive input selection approach. This corresponds to a $45 \%$ reduction of the productivity loss due to the required on-machine measurements. 

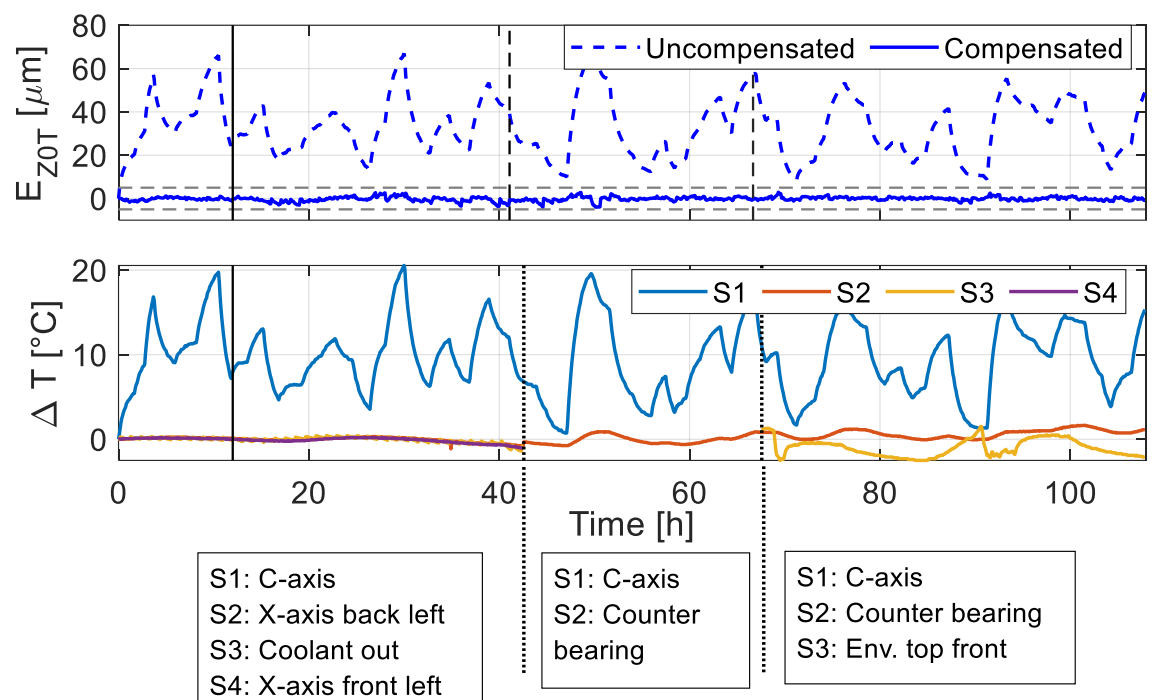

Fig. 10. Compensation results for the thermal error $\mathrm{E}_{\mathrm{Z} 0 \mathrm{~T}}$ using the TALC in combination with the adaptive input selection and the selected model inputs using the experimental setup described in [54]. The solid vertical line indicates the end of the training phase and the time of the first model setup. The dashed vertical lines represent the exceedance of the action control limit and the dotted vertical lines illustrate the change of selected input variables within the model updates after the triggered relearning phase. The defined action control limits are illustrated by the dashed horizontal lines
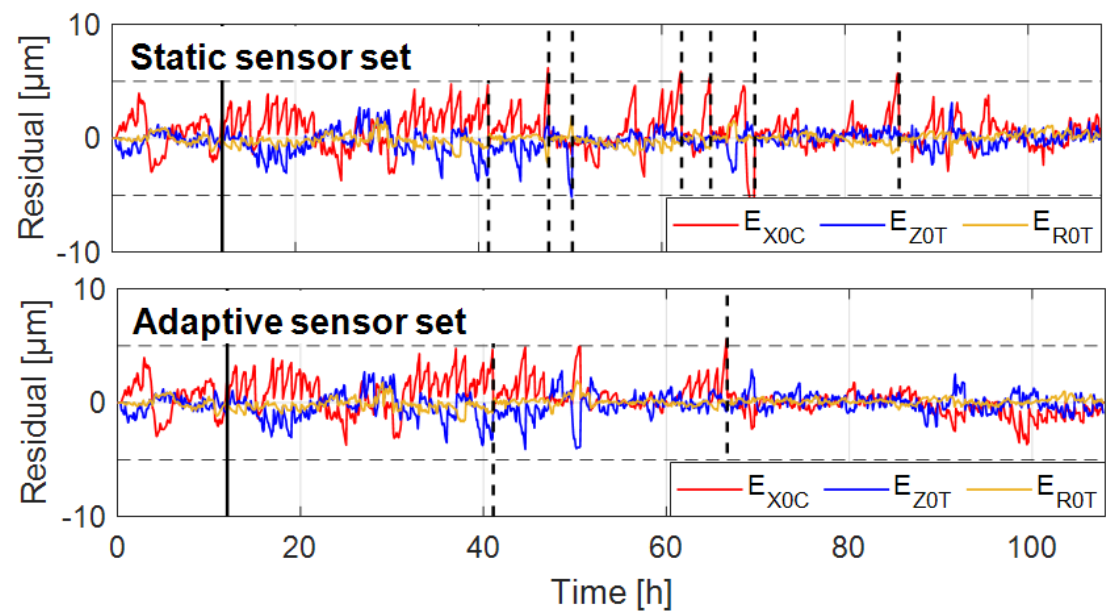

Fig. 11. Comparison of the compensation results for the translational errors of the $\mathrm{C}$-axis using the TALC with a static and an adaptive sensor set [54]. The black vertical line marks the end of the training phase, the vertical dashed lines indicate the recalibration of the model with geometrical on-machine measurements

In order to demonstrate the industrial feasibility and the accuracy improvement due to the TALC, Blaser et al. [55] applied the TALC during the manufacturing of thermal test-pieces. The used thermal test-piece was developed by Wiessner et al. [56] and is able to represent the three translation and one rotational thermal errors of a vertical rotary axis over eight time steps. The corresponding errors of the thermal test-piece with inactive and active TALC are illustrated in Fig. 12. The results show that the TALC reduces the thermal errors on the produced thermal test-piece by up to $91 \%$. 
The TALC and the adaptive input selection provide an applicable basis for selfoptimizing thermal compensation strategies for machine tools. The combination of these two methods significantly increases the self-learning ability for thermal compensation models, so that the operator interaction is reduced to a minimum and no specific knowledge of the thermal behaviour is needed in prior. Consequently, the machine tools can autonomously realize a site- and situation-specific adaption of the thermal compensation models.
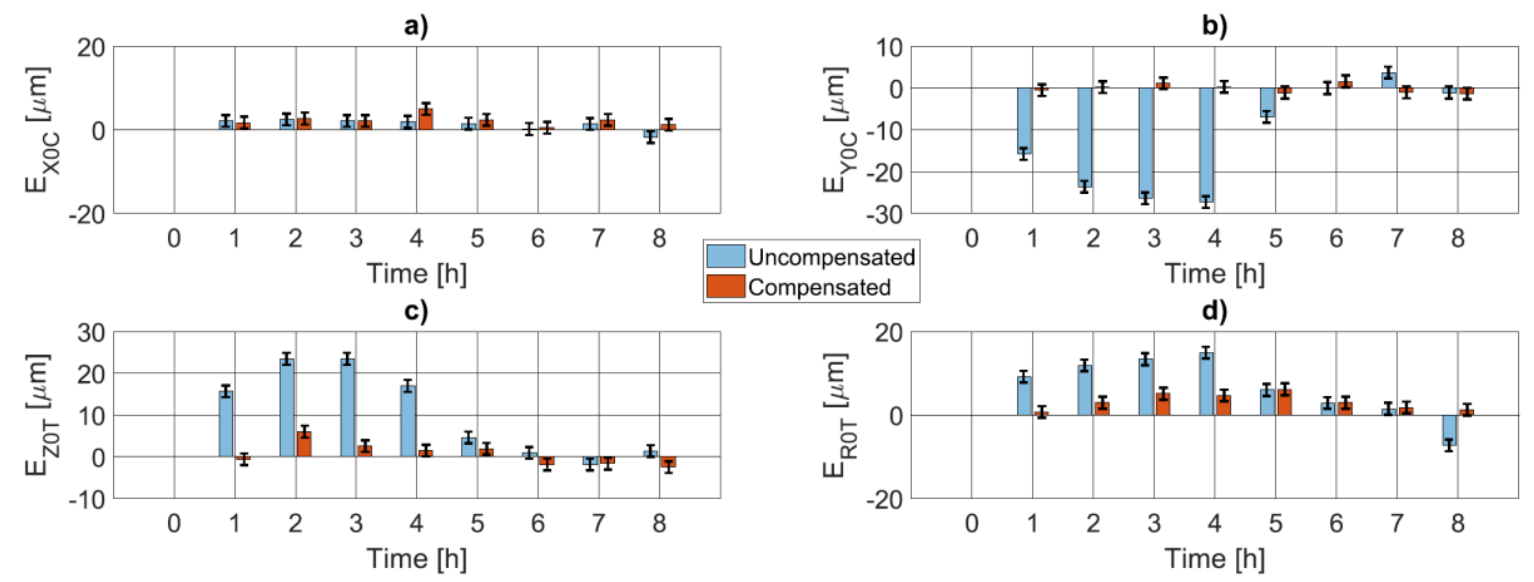

Fig. 12. Identified thermal errors measured with the thermal-test piece with and without active TALC [54]

\section{MACHINE ERROR COMPENSATION}

While Chapter 5 shows how self-learning and self-adaptation in combination with physical modelling transfers adjustment tasks from the operator to the machine tool for correction of thermal errors, this chapter shows a similar approach for the correction of dynamic behavior of the uncontrolled mechanical machine tool structure, which today is typically done during path planning by a skilled human NC-programmer. And again, it is one aspect of the intelligent machine tool to adjust parameters in future automatically. Increasing demands on performance, especially energy efficiency are the driver for the on-going increase of part accuracy requirements together with cost reduction and productivity improvements over the years. This development has been pointed out by Taniguchi [57] in 1983 in detail. Increased part accuracy requirements are directly linked to machine tool (MT) accuracy performance and juxtaposed to productivity requirements. Path and speed profile adjustment become necessary. Application of corrections as pointed out in [58], especially on NC-side is the common way to increase machine accuracy with justifiable effort required and without interaction of human operators, which is exposed in the following.

\subsection{SYSTEM UNDERSTANDING}

A general system understanding [59] of the various interactions in machine tools is given in Fig. 13. Based on the movement set points, the numerical control (NC), consisting of setpoint value generation and control interacts with the electro-mechanical system. Here, the amplifier, the electric drives and the mechanical components such as transmission elements 
and the moving axes but also the other structural components are included. As significant property, the feed-back for the control is limited to the sensors arranged as semi-closed and closed-loop configuration. The entity of control and the part of the system where feed-back information is available from sensors on-line is the controlled electromechanical system.

Unfortunately, the real movements of the tool centre point (TCP) are significantly influenced by contributions of the remaining uncontrolled structure, outside of control loops, on which the control has only limited influence. During the design of a machine tool system, major efforts are applied to minimise the effects of the uncontrolled structure, such as straightness and Abbé errors, dynamic crosstalk, in-talk but also structural thermal deformations etc. Typically, these effects are intended to be corrected by the CNC [60] after having carefully exploited the mitigation means by design. Limitations for this approach are the repeatability of the mechanical system and the capability, resp. uncertainty of the metrology approach that is applied to gather the behaviour of the uncontrolled system. Repeatability is the systematic behaviour of the system which can be represented quantitatively based on on-line attainable system states.

Another property of these systems is the fact that the controlled axes, given by the concept of having a serial axis configuration, can only influence directions of motions which are in parallel to the direction of the individual drive. Effects in other direction than the direction of the drive itself require structural damping in order to become mitigated. Alternative design means can be applied to minimise cross-axis effects as shown later.

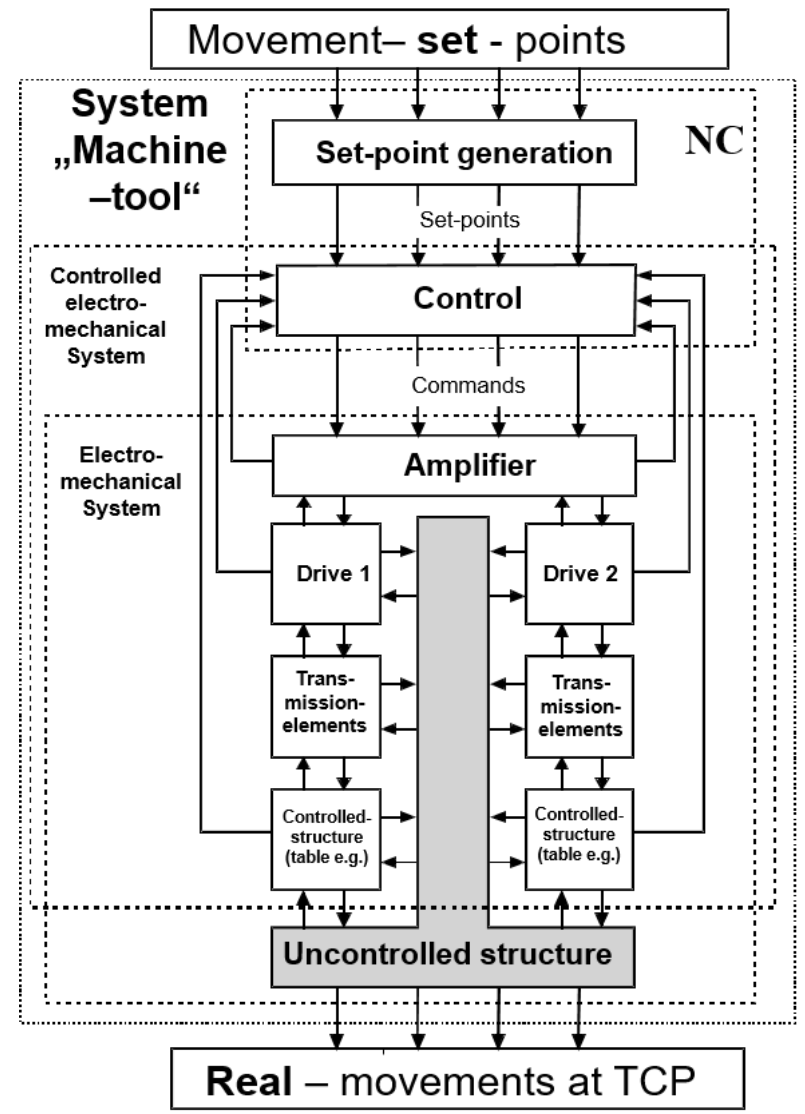

Fig. 13. System understanding of the chain between set-points and the real movements at the TCP given for mechatronic systems such as machine tools 


\subsection{DYNAMIC COMPENSATION VIA NC}

On the metrology side, the ISO 230 series provides specific procedures for the quantification of the geometric behaviour. While in ISO 230-1:2012 [61] methods are specified for testing the accuracy of machine tools, operating either under no-load or under quasi-static conditions, by means of geometric and machining tests, in ISO 230-2:2014 [62] the accuracy and repeatability of numerically controlled axes is regarded. How to handle this class of effects is be discussed in the next section. Covering the interaction of more than one axis, ISO 230-4 [63] provides a procedure for testing and evaluation of circular paths created by two interpolating linear axes. These standards provide the quantified behavior of the MT which can directly be applied for NC-compensation as input for compensation tables but also for the validation of the behavior after the compensation is applied. Explicitly in ISO 16907/TR:2015(E) [64], the case of dynamic forces due to high-speed machine motions are not covered.

As pre-requisite, the systematic share of dynamic effects has to be revealed and quantified. Important are appropriate measurement devices such as the cross-grid by Heidenhain [65] or the R-Test [66], which allow to capture the spatial nature of the dynamic effects.

For the spatial quantification of cross-talk effects, the measurement of dynamic circles in the three coordinate planes has been proposed [66]. Based on the quite systematic nature of the inertial based crosstalk effects, shown in Fig. 14, proportionality factors describing the dependency of lateral displacements in the three Cartesian directions caused by arbitrary axis accelerations depending on the actual location in the working envelope of the MT are derived.

Based on these measurements systematic effects can be corrected as long as the effects can be quantified and as additional pre-requisite, the $\mathrm{NC}$ is capable to use the internally available values for corrective actions. An example of such capabilities is the Dynamic Precision by Heidenhain [67]: The CTC (Cross Talk Compensation) allows to compensate for acceleration dependent position deviations by using the actual axis acceleration for derivation of position corrections. The Heidenhain NC-functionalities LAC (Load adaptive control) and PAC (Position adaptive control) consist of adapting the control parameters based on actual load / work-piece mass and based on the actual axis position. These functionalities increase the contour accuracy together with potentially increasing productivity by higher feed-rates by exerting influence on the uncontrolled system.

As MTsa high degree of repeatability, which is a pre-requisite for all kinds of corrections, the repetitive behaviour can be used for the iterative application of correction means. Iterative learning control (ILC) is such an approach [68], which iteratively improves the path behaviour based on the basis of previous runs. ILC can be applied if the machining task is medium to high volume production and therefore the same trajectories are to be followed consecutively. But upon feature segmentation of paths with parametrized path features, the applicability of ILC can be extended down to single piece production, with the prerequisite that trained data for each feature can be retrieved from the expert system.

Figure 15 illustrates the concept: Without application of ILC the example trajectory shows significant path deviations (red). Consecutively, measurement values of the axis encoders CO-ILC (ENC) or measurement results at the TCP with a cross grid CO-ILC (KGM) 
are used for a convex optimisation approach. As expected not the same amount of improvement can be obtained: Cross grid measurements (blue) show a quite good accordance of the TCP trajectory with the desired path in the middle of the dashed lines. If the axis encoder values are used for the learning procedure, obviously effects between the encoder locations and the TCP are due to the uncontrolled structure and remain hidden.
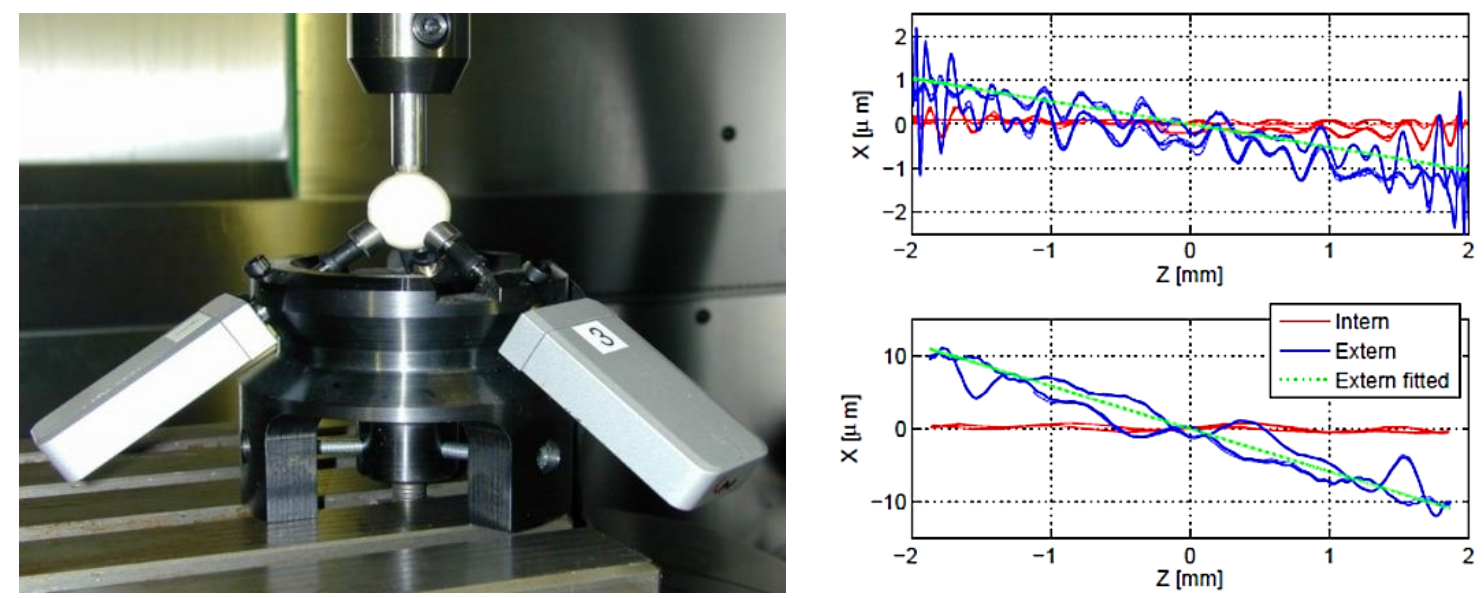

Fig. 14. R-Test for dynamic measurements: left: measurement setup: precision sphere and three incremental probes; right: representation of circular trajectories in $Y Z$-plane for a jerk of $0.5 \mathrm{~m} / \mathrm{s}^{3}$ (top) and $4.5 \mathrm{~m} / \mathrm{s}^{3}$ (bottom) [67]

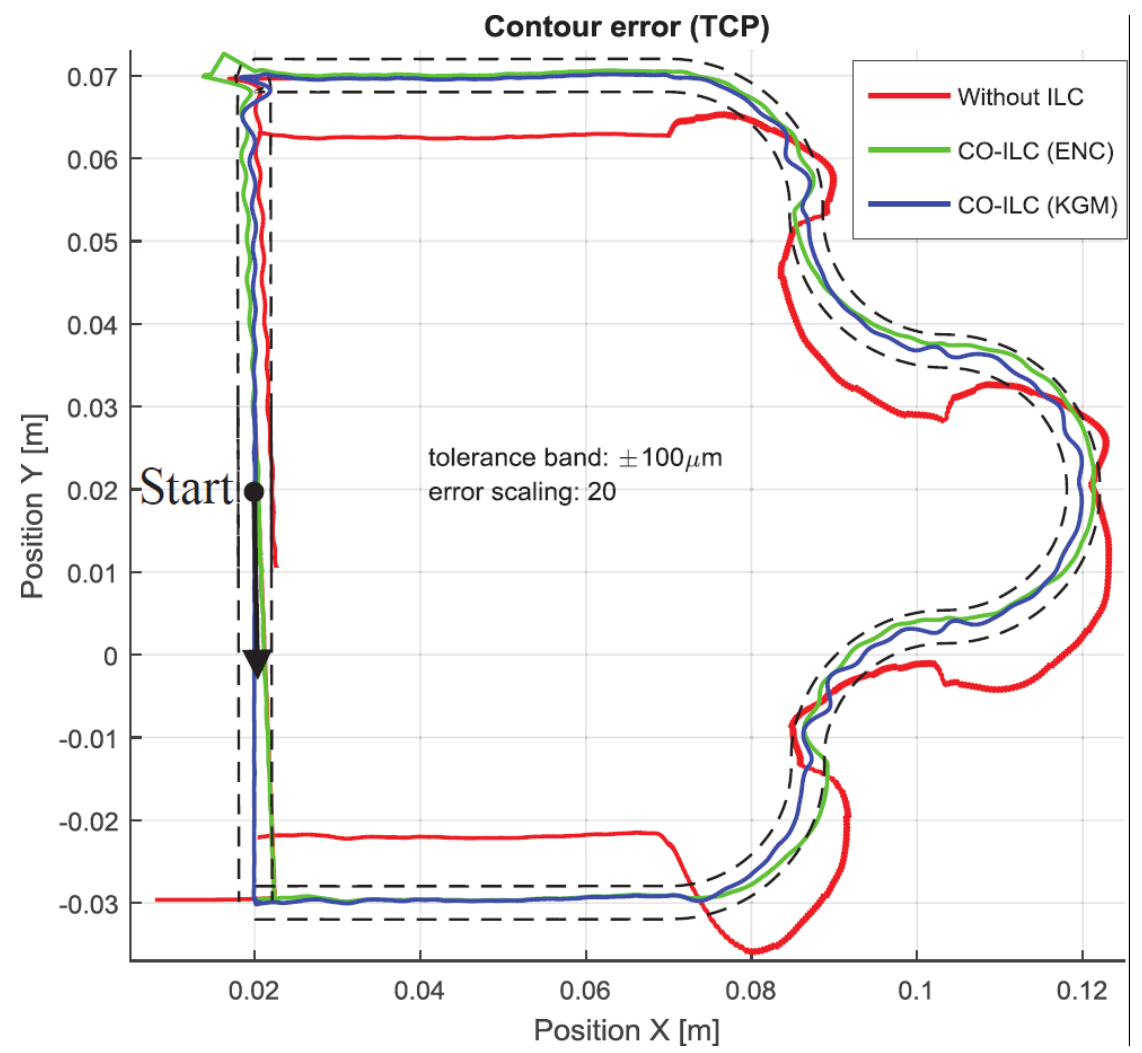

Fig. 15 . Comparison of path deviations: Path deviations with standard control scheme (red), Path measured on encoder level applying ILC convex optimisation approach (green), Path measured at TCP applying

ILC convex optimisation approach (blue), [68] 


\section{CONCLUSION}

Manufacturing technology is submerged to drastic changes. These stem from the dictatorship of ever-increasing productivity, accuracy, sustainability but also arise from the development of enabling technologies from outside of manufacturing. It is recognized that cheap devices developed in incredible mass production for the consumer market take over the lead in the equipment of production machines. Large number of sensors, optical, acoustical monitoring of processes and machines, communication technologies and artificial intelligence provide the technological basis for future manufacturing systems. This fuels the exposed vision of machine tools with functionalities of the operator integrated in an intelligent and self-learning expert system, which then increases the autonomy of the machine, reduces setup times and stores and safeguards implicit knowledge of operators. Taking this as the overall development goal, different technological research vectors and their already available results are shown, which eventually become aspects of the intelligent manufacturing machine. Setup of grinding processes is an experience based and laborious task. AI with the support of physical modelling so called physics supported AI can be seen as corner stone of an intelligent grinding machine. Chatter is limiting the productivity in cutting with geometrically defined cutting edges. Despite being well researched, industrially viable solutions for reliable chatter suppression are lacking. Here also physics supported AI approaches are of benefit showing that even with AI approach human intelligence and system understanding is still valuable. Increasing the accuracy are requirements that benefit from AI on the basis of a physical model of the system.

The understanding of the system with human intelligence is the key technology to gain accuracy increase beyond what can be achieved in manufacturing of the machine tool. This class of technologies is shown to be useful already for the autonomous suppression of thermal and dynamic misbehavior of machine tools.

\section{REFERENCES}

[1] UEDA K., 1992, An Approach to Bionic Manufacturing Systems Based on DNA-Type Information, Proc. of the ICOOMS'92, 303-308.

[2] MALSHE A., RAJURKAR K., SAMANT A., NOERGAARD-HANSEN H., BAPAT S., JIANG W., 2013, Bioinspired Surfaces for Advanced Applications, CIRP Annals, 2/2, 607-628.

[3] BYRNE G., DiMitrov D., MONOSTORI L., TETI R., VAN HOUTEN F., WERTHEIM R., 2018, Biologicalisation: Biological Transformation in Manufacturing, CIRP Journal of Manufacturing Science and Technology, 21, 1-32.

[4] EL MARAGHY H., MONOSTORI L., SCHUH G., EL MARAGHY W., 2021, Evolution and Future of Manufacturing Systems, CIRP Annals 70/2, 35-658.

[5] WEGENER K., SPIERINGS AB., STAUB A., 2020, Bioinspired Intelligent SLM Cell, 12th CIRP Conference on Intelligent Computation in Manufacturing Engineering (ICME), Procedia CIRP, 88, 624-630.

[6] MÖHRING H-C., WIEDERKEHR P., ERKORKMAZ K., KAKINUMA Y., 2020, Self-Optimizing Machining Systems, CIRP Annals 69/2, 740-763. https://doi.org/10.1016/j.cirp.2020.05.007.

[7] DALAEE M., 2020, Enhancement in Deposition rate of LASER DMD, PhD-thesis ETH Zürich, No. 26987.

[8] WEGENER K., SPIERINGS A.B., TETI R., CAGGIANO A., KNÜTTEL D., STAUB A., 2021, A Conceptual Vision for a Bio-Intelligent Manufacturing Cell for Selective Laser Melting, CIRP Journal of Manufacturing Science and Technology, 34, 61-83. 
[9] MC CANN R., OBEIDI M.A., HUGHES C., MC CARTHY E., 2021, In-Situ Sensing, Process Monitoring and Machine Control in Laser Powder Bed Fusion: A Review, Additive Manufacturing, https://doi.org/10.1016/ j.addma.2021.102058

[10] RENKEN V., von FREYBERG A., SCHÜNEMANN K., PASTORS F., FISCHER A., 2019, In-Process ClosedLoop Control for Stabilising the Melt Pool Temperature in Selectivelaser Melting, Progress in Additive Manufacturing, 4/4, 411-421, https://doi.org/10.1007/s40964-019-00083-9.

[11] FLEMING T.G., NESTOR S.G.L., ALlEN T.R., BOUKHALED M.A., SMITH N.J., FRASER J.M., 2020 , Tracking and Controlling the Morphology Evolution of 3D Powder-Bedfusion in Situ Using Inline Coherent Imaging, Additive Manufacturing, 32, doi:10.1016/j.addma.2019.100978.

[12] BARSCHDORFF D., MONOSTORI L., 1991, Neural Networks - Their Applications and Perspectives in Intelligent Machining, Computers in Industry, 17, 101-119.

[13] MONOSTORI L., MARKUS A., VAN BRUSSEL H., WESTKÄMPER E., 1996, Machine Learning Approaches to Manufacturing, CIRP Annals, 45/2, 675-712.

[14] PHAM D.T., PHAM P.T.N., 1999, Artificial Intelligence in Engineering, International Journal of Machine Tools and Manufacture, 39, 937-949.

[15] BYRNE G., DAMM O., MONOSTORI L., TETI R., VAN HOUTEN F., WEGENER K., WERTHEIM R., SAMMLER F., 2021, Towards High Performance Living Manufacturing Systems - A New Convergence Between Biology and Engineering, CIRP Journal of Manufacturing Science and Technology, 34, 6-21.

[16] ROWE W.B., YAN L., INASAKI I., MALKIN S., 1994, Applications of Artificial Intelligence in Grinding, CIRP Annals, 43/2 521-531, https://doi.org/10.1016/S0007-8506(07)60498-3.

[17] SAKAKURA M., INASAKI I., 1992, A Neural Network Approach to the Decision Making Process for Grinding Operations, CIRP Annals, 41, 353-356. https://doi.org/10.1016/S0007-8506(07)61221-9.

[18] MORGAN M.N., CAI, A.R.. GUIDOTTI ALLANSON D.R., MORUZZI J., ROWE W., 2007, Design and Implementation of an Intelligent Grinding Assistant System, International Journal of Abrasive Technology, 1/1, 106135.

[19] BARRENETXEA D., MARQUINEZ J. I., ÁlVAREZ J., FERNÁNDEZ R., GALLEGO I., MADARIAGA J., GARITAONAINDIA I. , 2012, Model-Based Assistant Tool for the Setting-up and Optimization of Centerless Grinding Process, Machining Science and Technology, 16/4, 501-523.

[20] GOTTLOB G., FRÜHWIRTH T., HORN W., 1990, Expertensysteme, Springer Vienna.

[21] WATERMAN D.A., 1986, A Guide to Expert Systems. The Teknowledge Series in Knowledge Engineering, Reading-Mass, a.o. Addison-Wesley.

[22] GAEGAUF F., 2011, Technologie Schafft Wettbewerbsvorteile, Schweizer Präzisionstechnik, 26-28.

[23] GHOLAMI M.H., AZIZI M.R., 2014, , Constrained Grinding Optimization for Time, Cost, and Surface Roughness Using NSGA-II, The International Journal of Advanced Manufacturing Technology, 73/5, 981-988.

[24] KWAK J-S., 2005, Application of Taguchi and Response Surface Methodologies for Geometric Error in Surface Grinding Process, International Journal of Machine Tools and Manufacture, 45/3, 327-334.

[25] SATHYANARAYANAN G., JOSEPH LIN I., CHEN M-K., 1992, Neural Network Modelling and Multiobjective Optimization of Creep Feed Grinding of Superalloys, International Journal of Production Research, 30/10, 24212438.

[26] ZADEH L., 1963, Optimality and Non-Scalar-Valued Performance Criteria, IEEE Transactions on Automatic Control, 8/1, 59-60.

[27] LIAO T.W., CHEN L., 1994, A Neural Network Approach for Grinding Processes: Modelling and Optimization, International Journal of Machine Tools and Manufacture, 34/7, 919-937.

[28] WEN X.M., TAY A.A.O., NEE A.Y.C., 1992, Micro-Computer-Based Optimization of the Surface Grinding Process, Journal of Materials Processing Technology, 29/1, 75-90.

[29] PAWAR P.J., RAO R.V., DAVIM J.P., 2010, Multiobjective Optimization of Grinding Process Parameters Using Particle Swarm Optimization Algorithm, Materials and Manufacturing Processes, 25/6, 424-431.

[30] RAO R., PAWAR P., 2010, Grinding Process Parameter Optimization Using Non-Traditional Optimization Algorithms, Proceedings of the Institution of Mechanical Engineers, Part B, Journal of Engineering Manufacture, 224/6, 887-898.

[31] MANIMARAN G., KUMAR M.P., 2013, Multiresponse Optimization of Grinding AISI 316 Stainless Steel Using Grey Relational Analysis, Materials and Manufacturing Processes, 28/4, 418-423.

[32] SIDDIQUEE A.N., KHAN Z.A., MALLICK Z., 2010, Grey Relational Analysis Coupled with Principal Component Analysis for Optimisation Design of the Process Parameters in In-Feed Centreless Cylindrical Grinding, The International Journal of Advanced Manufacturing Technology, 46/9, 983-992.

[33] RUDRAPATI R., PAL P.K., BANDYOPADHYAY A., 2016, Modeling and Optimization of Machining Parameters in Cylindrical Grinding Process, The Inter. J. of Advanced Manufacturing Technology, 82/9, 2167-2182. 
[34] KRAJNIK P., KOPAC J., SLUGA A., 2005, Design of Grinding Factors Based on Response Surface Methodology, Journal of Materials Processing Technology, 162, 629-636.

[35] MAIER M., RUPENYAN A., BOBST C., WEGENER K., 2020, Self-Optimizing Grinding Machines Using Gaussian Process Models and Constrained Bayesian optimization, The International Journal of Advanced Manufacturing Technology, 108/1, 539-552.

[36] ALTINTAS Y., BER A.A., 2001, Manufacturing Automation: Metal Cutting Mechanics, Machine Tool Vibrations, and CNC Design, Appl. Mech. Rev., 54/5, B84.

[37] NAMAZI M., ALTINTAS Y., ABE T., RAJAPAKSE N., 2007, Modeling and Identification of Tool Holder-Spindle Interface Dynamics, International Journal of Machine Tools and Manufacture, 47, 1333-1341.

[38] LÖSER M., GROSSMANN K., 2016, Influence of Parameter Uncertainties on the Computation of Stability Lobe diagrams, Procedia CIRP, 46, 460-463.

[39] POSTEL M., BUGDAYCI B., MONNIN J., KUSTER F., WEGENER K., 2018, Improved Stability Predictions in Milling Through More Realistic Load Conditions, Procedia CIRP, 77, 102-105.

[40] GROSSI N., SALLESE L., SCIPPA A., CAMPATELLI G., 2014, Chatter Stability Prediction in Milling Using Speed-Varying Cutting Force Coefficients, Procedia CIRP, 14, 170-175.

[41] FRIEDRICH J., HINZE C., RENNER A., VERL A., LECHLER A., 2017, Estimation of Stability Lobe Diagrams in Milling with Continuous Learning Algorithms, Robotics and Computer-Integrated Manufacturing, 43, $124-134$.

[42] CHERUKURI H., PEREZ-BERNABEU E., SELLES M., SCHMITZ T., 2019, Machining Chatter Prediction Using a Data Learning Model, Journal of Manufacturing and Materials Processing, 3, 45.

[43] POSTEL M., BUGDAYCI B., KUSTER F., WEGENER K., 2020, Neural Network Supported Inverse Parameter Identification for Stability Predictions in Milling, CIRP Journal of Manufacturing Science and Technol., 29, 71-87.

[44] POSTEL M., 2020, Model-Supported Improvement of Stability Limit Predictions in Milling Through Artifical Neural Networks, PhD thesis. (IWF), ETH Zurich.

[45] POSTEL M., BUGDAYCI B., WEGENER K., 2020, Ensemble Transfer Learning for Refining Stability Predictions in Milling Using Experimental Stability States, The International Journal of Advanced Manufacturing Technology, 107, 4123-4139.

[46] FRIEDRICH J., HINZE C., LECHLER A., VERL A., 2016, On-line Learning Artificial Neural Networks for Stability Classification of Milling Processes, International Conference on Advanced Intelligent Mechatronics (AIM), 357-364.

[47] MAYR J., JEDRZEJEWSKI J., UHLMANN E., ALKAN DONMEZ M., KNAPP W., HÄRTIG F., WENDT K., MORIWAKI T., SHORE P., SCHMITT R., BRECHER C., WÜRZ T., WEGENER K., 2012, Thermal Issues in Machine Tools, CIRP Annals - Manufacturing Technology, 61/2, 771-791.

[48] GEBHARDT M., MAYR J., FURRER N., WIDMER T., WEIKERT S., KNAPP W., 2014, High Precision Greybox Model for Compensation of Thermal Errors on Five-Axis Machines, CIRP Annals - Manufacturing Technology, 63/1, 509-512.

[49] BRECHER C., HIRSCH P., WECK M., 2004, Compensation of Thermo-Elastic Machine Tool Deformation Based on Control Internal Data, CIRP Annals - Manufacturing Technology, 53/1, 299-304.

[50] MAREŠ M., HOREJŠ O., HAVLÍK L., 2020, Thermal Error Compensation of a 5-Axis Machine Tool Using Indigenous Temperature Sensors and CNC Integrated Python Code Validated with a Machined Test Piece, Precision Engineering, 66, 21-30.

[51] BLASER P., PAVLIČEK F., MORI K., MAYR J., WEIKERT S., WEGENER K., 2017, Adaptive Learning Control for Thermal Error Compensation of 5-Axis Machine Tools, Journal of Manufacturing Systems, 44, 302-309.

[52] MAYR J., BLASER P., RYSER A., HERNANDEZ-BECERRO P., 2018, An Adaptive Self-Learning Compensation Approach for Thermal Errors on 5-Axis Machine Tools Handling an Arbitrary Set of Sample Rates, CIRP Annals, 67/1, 551-554.

[53] ZIMMERMANN N., LANG S., BLASER P., MAYR J., 2020, Adaptive Input Selection for Thermal Error Compensation Models, CIRP Annals, 69/1, 485-488.

[54] BLASER P., MAYRJ., WEGENER, K., 2020, Simulation Based Comparison of Thermal Error Modelling Methods for Machine Tools, In euspen Special Interest Group Meeting, Thermal Issues, 2-5.

[55] BLASER P., MAYR J., WEGENER K., 2019, Long-Term Thermal Compensation of 5-Axis Machine Tools Due to Thermal Adaptive Learning Control, MM Science Journal, 4, 3164-3171.

[56] WIESSNER M., BLASER P., BÖHL S., MAYR J., KNAPP W., WEGENER K., 2018, Thermal Test Piece for 5- Axis Machine Tools, Precision Engineering, 52, 407-417.

[57] TANIGUCHI N., 1983, Current Status in, and Future Trends of, Ultraprecision Machining and Ultrafine Materials Processing, Annals of the CIRP, 32/2, 573-582.

[58] SARTORI S., 1995, Geometric Error Measurement and Compensation of Machines, Annals of the CIRP, 44/2, 599-609. 
[59] WEIKERT S., 2000, Beitrag zur Analyse des dynamischen Verhaltens von Werkzeugmaschinen, Diss. ETHZ No 13596, doi:10.3929/ethz-a-003896403.

[60] SCHWENKE H., 2008, Geometric Error Measurement and Compensation of Machines - An update, Annals of the CIRP, 57/2, 660-675.

[61] ISO 230-1:2012, Test Code for Machine Tools - Part 1: Geometric Accuracy of Machines Operating Under Noload or Quasi-Static Conditions.

[62] ISO 230-2:2014, Test Code for Machine Tools - Part 2: Determination of Accuracy and Repeatability of Positioning of Numerically Controlled Axes.

[63] ISO 230-4, Test code for machine tools - Part 4: Circular Tests for Numerically Controlled Machine Tools.

[64] ISO/TR 16907:2015(E), Machine tools - Numerical Compensation of Geometric Errors.

[65] http://www.heidenhain.com/site.html.

[66] THOMA S., HAAS T., NGUYEN M.H., WEIKERT S., WEGENER K., 2015, In- and Cross-Talk Evaluation of Different Machine Concepts, Landamap Conference.

[67] https://www.klartext-portal.de/de_DE/tipps/funktionen/dynamic-precision/.

[68] HAAS T., LANZ N., KELLER R., WEIKERT S., WEGENER K., 2016, Iterative Learning Approach for Machine Tools Using a Convex Optimisation Approach, Procedia CIRP, 46, 391-395. 